\title{
On the Settling Depth of Meltwater Escaping from beneath Antarctic Ice Shelves
}

\author{
Constantin W. Arnscheidt, ${ }^{\mathrm{a}}$ John Marshall, ${ }^{\mathrm{a}}$ Pierre Dutrieux, ${ }^{\mathrm{b}, \mathrm{c}}$ Craig D. Rye, ${ }^{\mathrm{a}, \mathrm{d}}$ And Ali Ramadhan ${ }^{\mathrm{a}}$

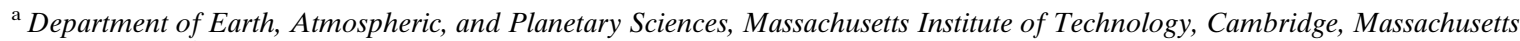 \\ ${ }^{\mathrm{b}}$ British Antarctic Survey, Natural Environment Research Council, Cambridge, United Kingdom \\ ${ }^{\mathrm{c}}$ Lamont-Doherty Earth Observatory of Columbia University, Palisades, New York \\ ${ }^{\mathrm{d}}$ Goddard Institute for Space Studies, New York City, New York
}

(Manuscript received 13 November 2020, in final form 16 April 2021)

\begin{abstract}
Antarctic glacial meltwater is thought to play an important role in determining large-scale Southern Ocean climate trends, yet recent modeling efforts have proceeded without a good understanding of how its vertical distribution in the water column is set. To rectify this, here we conduct new large-eddy simulations of the ascent of a buoyant meltwater plume after its escape from beneath an Antarctic ice shelf. We find that the meltwater's settling depth is primarily a function of the buoyancy forcing per unit width of the source and the ambient stratification, consistent with the classical theory of turbulent buoyant plumes and in contrast to previous work that suggested an important role for centrifugal instability. Our results further highlight the significant role played by localized variability in stratification; this helps explain observed interannual variability in the vertical meltwater distribution near Pine Island Glacier. Because of the vast heterogeneity in mass loss rates and ambient conditions at different Antarctic ice shelves, a dynamic parameterization of meltwater settling depth may be crucial for accurately simulating high-latitude climate in a warming world; we discuss how this may be developed following this work, and where the remaining challenges lie.
\end{abstract}

KEYWORDS: Ocean; Antarctica; Glaciers; Snowmelt/icemelt; Climate change

\section{Introduction}

A notable failure of the global coupled climate models included in the Coupled Model Intercomparison Project phase 5 (CMIP5; Taylor et al. 2012) has been their inability to hindcast important observed Southern Ocean climate trends such as surface cooling, surface freshening, and sea ice expansion (Turner et al. 2013; Jones et al. 2016; Kostov et al. 2018). The increase in the Antarctic meltwater anomaly over this period may have played an important role in driving the observed trends (Rye et al. 2020). Climate models typically neglect the anomalous freshwater flux due to net mass loss from the Antarctic ice sheet: this has increased over the past few decades to around $500 \mathrm{Gt} \mathrm{yr}^{-1}$ (Paolo et al. 2015; Rignot et al. 2019). Recent work suggests that the incorporation of this meltwater anomaly into climate models could help to explain the observed trends, resolving the discrepancy between observations and simulations (Bintanja et al. 2013; Rye et al. 2014; Bintanja et al. 2015; Rye et al. 2020). The incorporation of Antarctic glacial meltwater also has a significant impact on projections of future climate (Bronselaer et al. 2018; Golledge et al. 2019). Although there remains some disagreement about the magnitude of the climate impacts due to meltwater (Swart and Fyfe 2013; Pauling et al. 2016), understanding how to correctly represent this process in global climate models is clearly of importance.

In climate modeling studies, the meltwater has generally been represented as an externally imposed freshwater flux; this requires a starting assumption about where in the water column the glacial meltwater is situated. In many studies, glacial

Corresponding author: Constantin W. Arnscheidt, cwa@mit.edu meltwater has been introduced at or near the surface (Bintanja et al. 2013; Swart and Fyfe 2013; Rye et al. 2014; Bintanja et al. 2015; Hansen et al. 2016; Pauling et al. 2016; Bronselaer et al. 2018), or over a constant depth (Rye et al. 2020). Even though most of the melting occurs at depth, the meltwater might be expected to rise to the surface due to its relatively low density; however, this assumption is not supported by observations. For example, measurements of noble gas concentrations in the Ross Sea (Loose et al. 2009) and in the Amundsen Sea (Kim et al. 2016; Biddle et al. 2019) reveal vertical meltwater distributions centered at around 300-400-m depth. Near Pine Island Glacier, which is the source of a large fraction of the total Antarctic melt, Dutrieux et al. (2014b) found a large interannual variability in meltwater settling depth, with meltwater settling close to the surface in some years and hundreds of meters at depth in other years. A better understanding of what determines the settling depth of Antarctic glacial meltwater may greatly improve our understanding of ice-ocean interactions as well as their representation in climate models.

Aspects of glacial meltwater dynamics have been studied previously. In the Antarctic context, the priority has been to determine the rate and spatial distribution of sub-ice-shelf melting for given boundary conditions and forcings. To this end, studies have employed plume models in one (MacAyeal 1985; Jenkins 1991, 2011; Lazeroms et al. 2018) and two (Holland et al. 2007) dimensions, box models (Olbers and Hellmer 2010; Reese et al. 2018), and three-dimensional fluid dynamics simulations on the ice-shelf scale (Losch 2008; De Rydt et al. 2014; Mathiot et al. 2017). In an Arctic context, where meltwater is generally released from near-vertical tidewater glaciers at the ends of enclosed fjords instead of from underneath an ice shelf cavity, meltwater plumes have been studied using both one-dimensional plume theory and 
high-resolution numerical simulations (Xu et al. 2012, 2013; Sciascia et al. 2013; Kimura et al. 2014; Carroll et al. 2015; Cowton et al. 2015; Slater et al. 2015, 2016; Ezhova et al. 2018). Finally, Naveira Garabato et al. (2017) have studied the smallscale $(10-100 \mathrm{~m})$ fluid dynamics of meltwater escaping from underneath an Antarctic ice shelf, with an explicit focus on meltwater settling depth. They simulated the evolution of a meltwater plume in a two-dimensional plane perpendicular to the ice-shelf front, and argued that centrifugal instability, through its effect on lateral mixing, plays a dominant role in controlling the settling depth.

In this study, we revisit the small-scale fluid dynamics of meltwater ascent along an ice-shelf front after its escape from within the cavity. First, we describe an idealized meltwater ascent scenario, and introduce simple models for the meltwater's settling depth. Second, we describe new three-dimensional large-eddy simulations of the meltwater plume, and compare the results to the predictions of the simpler models. Third, we use our models to address observed interannual variability in meltwater settling depth near Pine Island Glacier. Finally, we discuss why a dynamic parameterization of meltwater settling depth could be crucial for accurately simulating high-latitude climate, and outline how such a parameterization could be implemented building in part on the work in this study.

\section{Theory and methods}

The object of this study is described schematically in Fig. 1. Much of the total mass loss from the Antarctic ice sheet stems from a small number of rapidly melting ice shelves; here, we focus on Pine Island Glacier, which is the source of a large fraction of the total mass loss (Rignot et al. 2019). The meltwater outflow from underneath the Pine Island ice shelf is concentrated in a narrow kilometer-scale flow at its western edge (Thurnherr et al. 2014; Naveira Garabato et al. 2017). A similarly narrow meltwater outflow may be a feature of many Antarctic ice shelves, as it is a consequence of a typical sub-iceshelf circulation (e.g., Grosfeld et al. 1997; Losch 2008). We investigate the dynamics of such a meltwater outflow by idealizing it as a prescribed, constant buoyancy source $F$, with width $L$, applied to the bottom of our model domain. In the real world, this buoyancy source is a function of complex melting and mixing processes beneath the ice shelf cavity; explicit consideration of these is beyond the scope of this paper. In this section, we outline the hierarchy of theoretical and modeling approaches that we will use.

\section{a. Simple scaling relationships}

The glacial meltwater escaping from underneath the ice shelf undergoes turbulent buoyant convection in a stratified ambient fluid. The theory of such processes was first developed by Morton et al. (1956). For plumes originating from a point source, far from any walls, this theory has yielded robust scaling laws for the plume's rise height in terms of the buoyancy source $F$ and the ambient stratification $N$. These scaling laws have been repeatedly confirmed in laboratory and experimental work (Turner 1986; Helfrich and Battisti
1991; Speer and Marshall 1995; Fabregat Tomàs et al. 2016). As described, for example, by Speer and Marshall (1995), as long as $N$ is substantially larger than the Coriolis parameter $f$, the only two parameters that could physically control the rise height are $F\left(\mathrm{~m}^{4} \mathrm{~s}^{-3}\right.$, consider an area-integrated buoyancy flux) and $N\left(\mathrm{~s}^{-1}\right)$. Assuming both terms to be constant, dimensional analysis then yields a vertical scale

$$
h_{N}=\left(\frac{F}{N^{3}}\right)^{1 / 4} \text {. }
$$

The real rise height $h$ is proportional to this vertical scale:

$$
h=a h_{N},
$$

where $a$ is a constant. Numerical experiments consistently yield a value of $a \simeq 2.6$ (e.g., Speer and Marshall 1995; Fabregat Tomàs et al. 2016).

In the case of the glacial meltwater outflow, however, the meltwater plume does not originate from a point source: it is rather in the shape of a line, where the total buoyancy forcing $F$ is distributed over some width $L$ (see Fig. 1). Therefore, we modify Eq. (1) by assuming that the two parameters exerting control over the rise height are the buoyancy source per unit width $F / L\left(\mathrm{~m}^{3} \mathrm{~s}^{-3}\right)$ and the ambient stratification $N\left(\mathrm{~s}^{-1}\right)$. Dimensional analysis now yields a vertical scale of

$$
h_{N}=\left(\frac{F}{L}\right)^{1 / 3} \frac{1}{N} \text {. }
$$

Again, the real rise height is proportional to this scale:

$$
h=a h_{N} .
$$

The constant of proportionality here could naively be expected to match the value observed for plumes originating from a point source $(a \simeq 2.6$ ), and the simulations we conduct in this study indeed confirm that it does (section $3 b$ ).

We emphasize that the buoyancy forcing $F / L$ is an abstraction. In the real world, the effective buoyancy flux escaping from underneath the ice shelf is a complex function of the meltwater dynamics within the cavity. For example, $F / L$ depends on the total melting within the cavity, on the spatial distribution of melting (because buoyant meltwater parcels released at depth will lose buoyancy on their ascent toward the ice-shelf front), and on the mixing with ambient cavity water. It also depends on the nature of the sub-ice-shelf circulation, and to what extent this focuses the outflow into a narrow jet as is the case for the Pine Island ice shelf. While $F / L$ could in principle be calculated using a sufficiently sophisticated subice-shelf model, our approach in this study will be to treat it primarily as a tunable parameter. This will allow us to gain an understanding of the ice-shelf-front-adjacent meltwater dynamics corresponding to a wide range of sub-ice-shelf melt scenarios.

\section{b. One-dimensional line plume model}

The scaling theory described above cannot account for the effects of nonuniform stratification [i.e., $N=N(z)$ ], and provides only limited physical insight. To improve upon it, we 


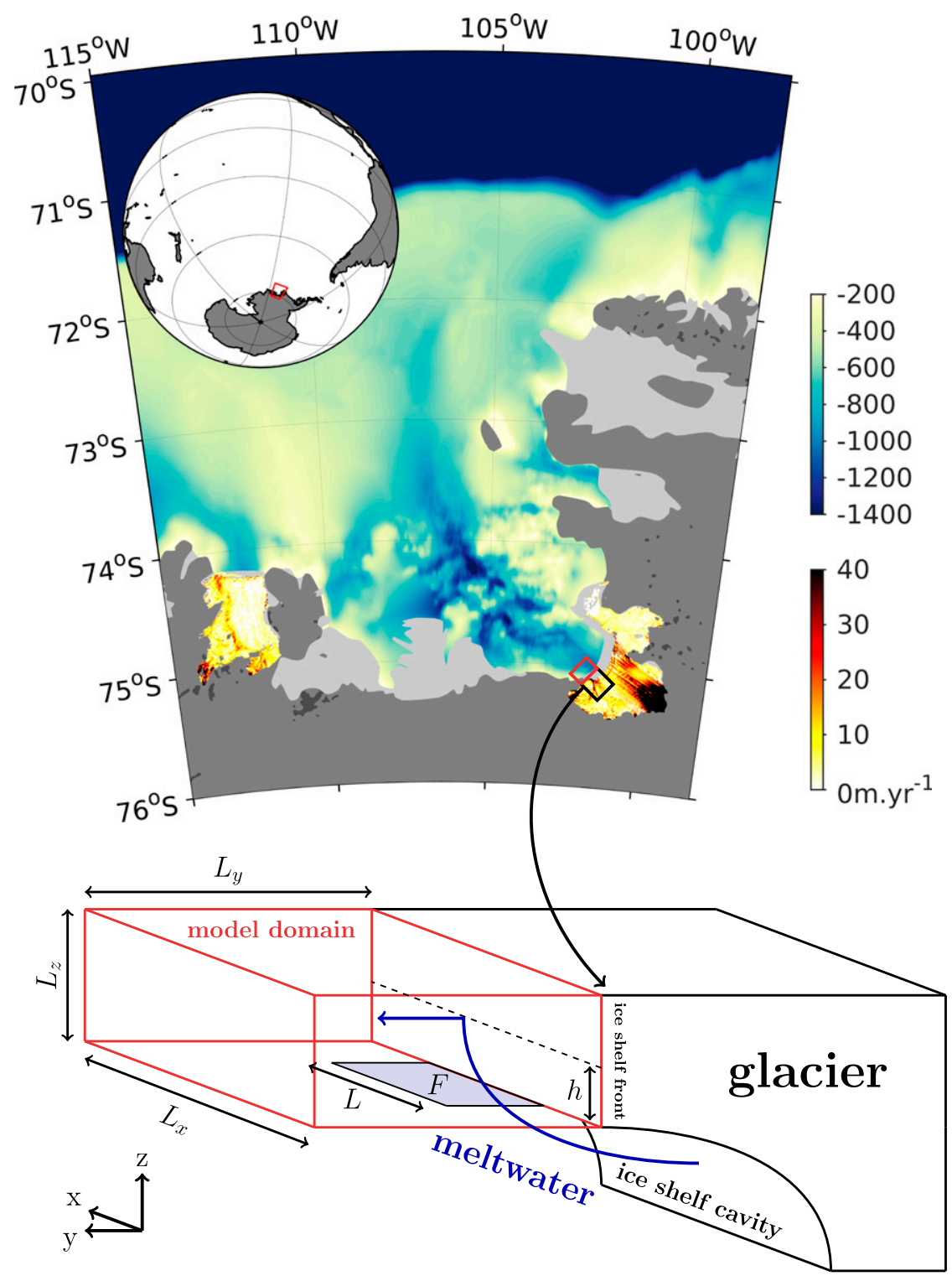

FIG. 1. A schematic describing the object of study. Melt rate data (gold/red) are from Shean et al. (2019) and Gourmelen et al. (2017), and bathymetry data (blue/green) are from Timmermann et al. (2010). Light, medium, and dark gray represent ice shelves, the Antarctic ice sheet, and rock outcrops, respectively. We focus on the meltwater outflow from beneath Pine Island Glacier, which is concentrated in a narrow kilometer-scale outflow at its western edge; this may be a feature of many Antarctic ice shelves. We idealize this meltwater outflow as a constant buoyancy source $F$, with width $L$, applied to the bottom of our model domain.

follow Morton et al. (1956) in constructing a one-dimensional vertical steady-state model of the buoyant plume. The original model of Morton et al. (1956) describes a point buoyancy source, and has been previously adapted to consider a point source of meltwater next to a vertical wall (Cowton et al. 2015; Carroll et al. 2015; Ezhova et al. 2018). One-dimensional models of buoyant line plumes rising underneath a sloping interface have also been widely applied to the study of sub-iceshelf meltwater dynamics (MacAyeal 1985; Jenkins 1991, 2011;
Lazeroms et al. 2018; Pelle et al. 2019). These models generally consider explicit fluxes of heat and salt instead of a generic buoyancy flux, as well as interactions across the ice-ocean interface.

Throughout this study we will assume that the dominant contribution to meltwater production is made below the ice shelf and that thermodynamic interactions between the plume and the ice shelf front itself (see Fig. 1) are negligible. For a buoyant plume originating from a line source next to a vertical 

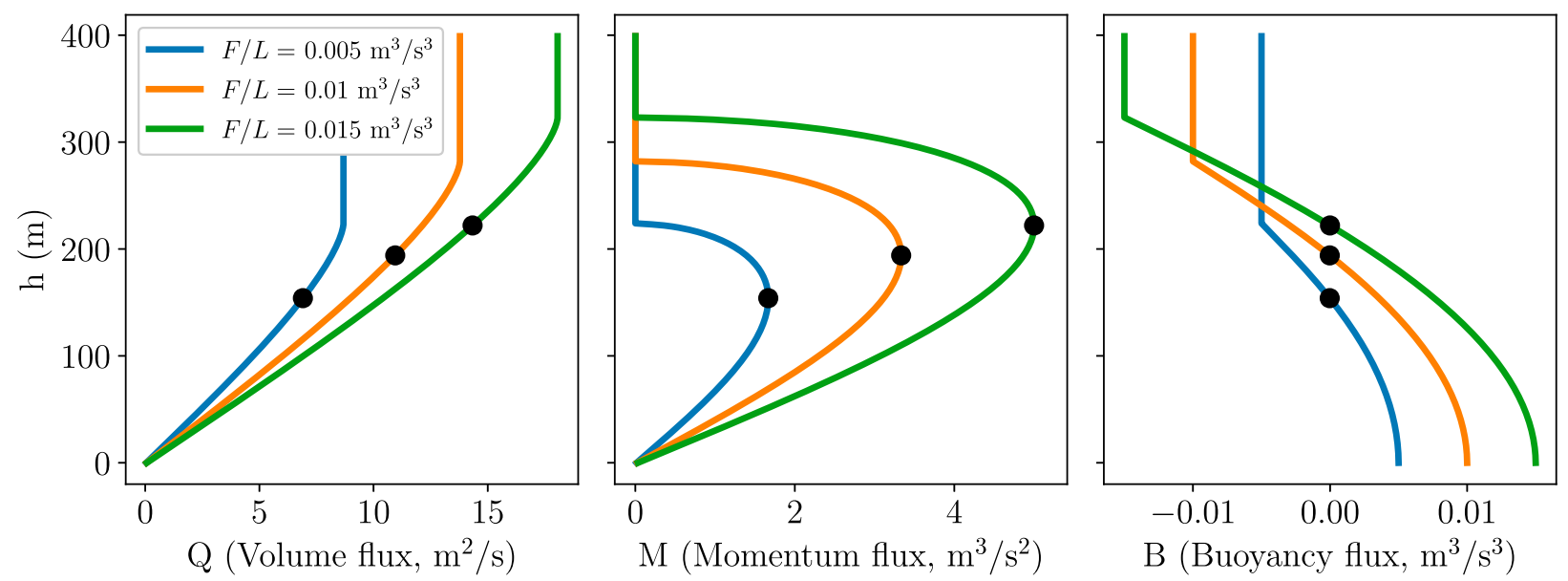

FIG. 2. Example solutions of the one-dimensional line plume model for different buoyancy forcings $F / L ; h=0$ represents the base of the ice shelf front. In each case, the black dot highlights the meltwater's settling depth; this is the level of neutral buoyancy, i.e., where $B(z)=0$.

wall, these assumptions lead to the following system of coupled ordinary differential equations (see appendix A):

$$
\begin{aligned}
& \frac{d Q}{d z}=\alpha \frac{M}{Q}, \\
& \frac{d M}{d z}=\frac{Q B}{M}, \\
& \frac{d B}{d z}=-Q N^{2} .
\end{aligned}
$$

Here $Q, M$, and $B$ are vertical fluxes per unit length of volume, momentum, and buoyancy, respectively; $N(z)$ is the ambient stratification, and $\alpha$ is a nondimensional entrainment coefficient. The model is solved for a given buoyancy forcing $F / L$ by setting $B=F / L$ at the bottom of the domain and integrating upward. The meltwater's settling depth is then given by the level of neutral buoyancy, which is where $B(z)=0$. Since $F / L$ and $N$ are the only dimensional input parameters, a characteristic vertical scale is again given by $h_{N}=(F / L)^{1 / 3} / N$.

Example solutions of this one-dimensional model are shown in Fig. 2, for a range of buoyancy forcings $F / L$. Here, the ambient stratification $N=3 \times 10^{-3} \mathrm{~s}^{-1}$, a realistic value for Pine Island Bay. Values used for the entrainment coefficient vary across the literature; here, we use $\alpha=0.15$, which is consistent with effective entrainment coefficients calculated from past numerical simulations of hydrothermal plumes (Jiang and Breier 2014; Fabregat Tomàs et al. 2016). We integrate our model equations using an eighth-order Runge-Kutta method (Prince and Dormand 1981).

\section{c. Three-dimensional large-eddy simulations}

To accurately study the behavior of the buoyant plume, and to evaluate the utility of the simpler theories described above, we conduct high-resolution simulations of the underlying small-scale fluid dynamics. Many previous studies have simulated the dynamics of geophysical plumes rising far from any walls (e.g., Lavelle 1995; Speer and Marshall 1995; Jiang and Breier 2014; Fabregat Tomàs et al. 2016). In the Arctic context, past studies have simulated glacial meltwater plumes rising next to a wall (Xu et al. 2012, 2013; Sciascia et al. 2013; Kimura et al. 2014; Carroll et al. 2015; Slater et al. 2015; Ezhova et al. 2018); the results are generally consistent with buoyant plume theory as long as the meltwater contribution from the ice face is small. However, it is unclear to what extent this is true of Antarctic meltwater plumes. Aside from the difference in geometry between these two contexts, studies of Arctic meltwater plumes typically neglect the effects of Earth's rotation, which in principle can have a substantial effect on settling depth (Fabregat Tomàs et al. 2016). While neglecting rotation may be reasonable within Greenlandic fjords (e.g., Straneo et al. 2010; Sciascia et al. 2013), it is not reasonable for meltwater escaping from beneath Antarctic ice shelves. For example, Naveira Garabato et al. (2017) showed using observations and two-dimensional simulations that the Coriolis force is responsible for a vigorous zonal jet next to the meltwater outflow from underneath the Pine Island ice shelf. They further argued that rotation had an important effect on the meltwater's settling depth, through the mechanism of centrifugal instability.

The vast majority of these numerical simulations of glacial meltwater plumes have used the Massachusetts Institute of Technology general circulation model in a nonhydrostatic configuration (MITgcm; Marshall et al. 1997). Here, we conduct new three-dimensional large-eddy simulations of a line glacial meltwater plume rising next to a wall using the software package Oceananigans.jl (Ramadhan et al. 2020). Oceananigans.jl is written in the high-level Julia programming language (Bezanson et al. 2017), simulates the rotating nonhydrostatic incompressible Boussinesq equations using a finite volume discretization similar to that of the MITgcm, and is optimized to run on graphical processing units (GPUs). The equations are integrated using a second-order Adams-Bashforth scheme with adaptive time stepping. The effects of subgrid scale processes are parameterized via an eddy viscosity and eddy diffusivity modeled using the anisotropic minimum dissipation (AMD) large-eddy simulation closure (Rozema et al. 2015). The AMD formalism was refined by Verstappen (2018) and validated for oceanrelevant scenarios by Vreugdenhil and Taylor (2018). 

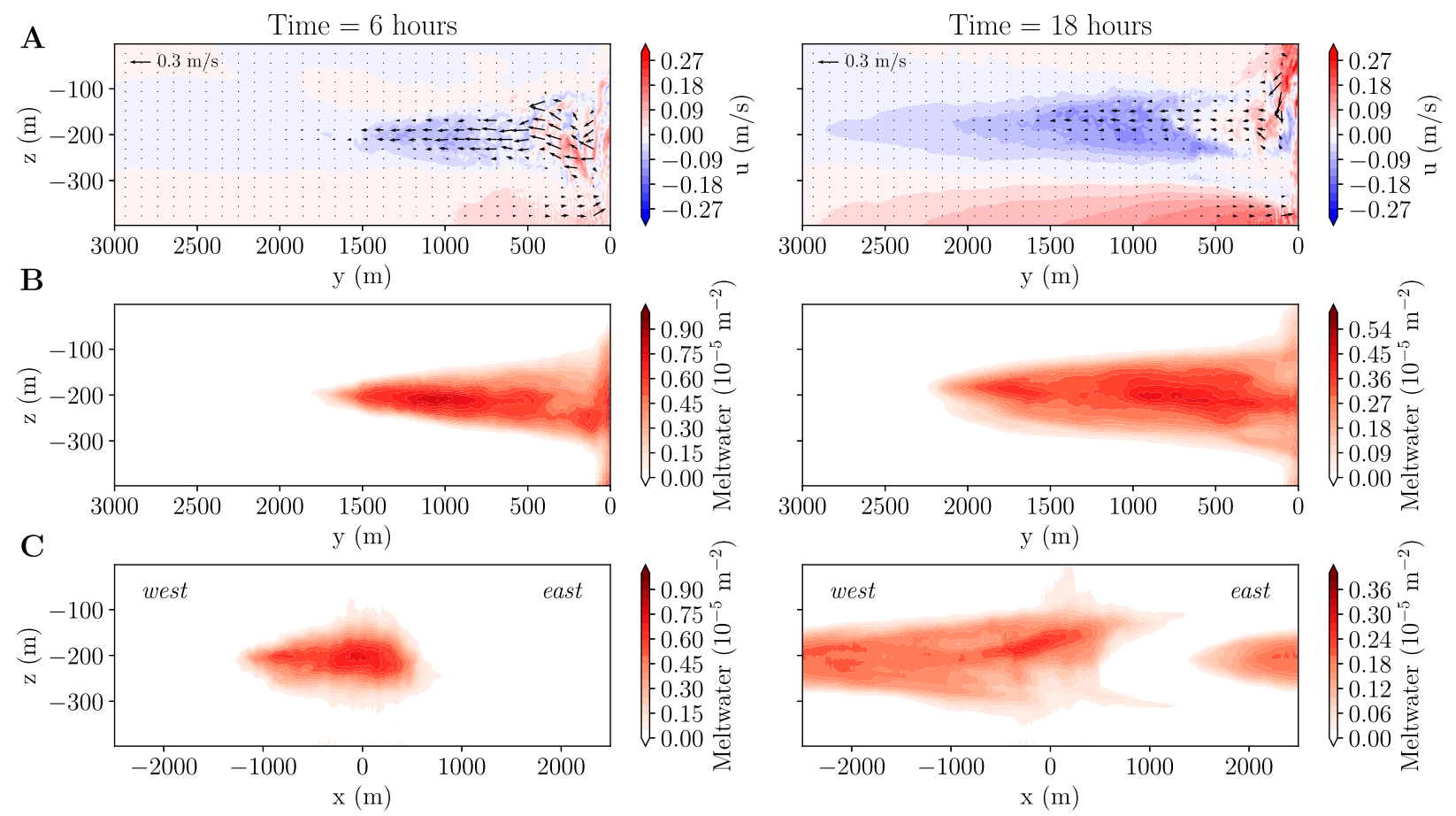

FIG. 3. Evolution of a simulated meltwater plume, after $6 \mathrm{~h}$ and after $18 \mathrm{~h}$. (a) A $y-z$ plane with $x=0$ (i.e., perpendicular to the ice shelf front) is depicted: arrows indicate the flow in this plane, while colors indicate the flow perpendicular to it. We see the development of a strong zonal flow, consistent with observations of the outflow from beneath the Pine Island ice shelf. (b) The zonally averaged meltwater distribution and (c) the meridionally averaged meltwater distribution are also depicted. Distributions have been normalized to integrate to 1. The meltwater outflow is deflected to the west by the Coriolis force, and eventually reenters the domain at the eastern boundary.

Our model domain follows the schematic in Fig. 1. The horizontal widths $L_{y}$ and $L_{x}$ are both set to $5 \mathrm{~km}$, while the depth of the ice shelf front $L_{z}$ is set equal to $400 \mathrm{~m}$ (approximately consistent with Pine Island Glacier; see Jenkins et al. 2010). The domain is reentrant in the zonal $x$ direction; free-slip and nonormal-flow conditions apply at the other boundaries. We use 512 grid cells in each horizontal direction and 96 grid cells in the vertical: this corresponds to a horizontal resolution of $9.77 \mathrm{~m}$ and a vertical resolution of $4.17 \mathrm{~m}$. We consider the evolution of temperature, salinity, and a passive tracer representing meltwater. Glacial meltwater escaping from underneath the ice shelf is represented as a constant buoyancy source $F$ applied to a horizontal area of length $L$ next to the southern edge of the domain (see Fig. 1). We conduct experiments both with varying $L$ and with $L$ set to a default value of $1 \mathrm{~km}$, which is broadly consistent with the meltwater outflow from beneath Pine Island Glacier (Naveira Garabato et al. 2017). The buoyancy source $F$ is implemented as a constant volumeconserving "virtual salinity flux" (Huang 1993; see appendix $\mathrm{B}$ for details). The Coriolis parameter $f$ is set to $-1.4 \times$ $10^{-4} \mathrm{~s}^{-1}$, appropriate for the latitude of Pine Island.

\section{Results}

\section{a. The simulated meltwater plume}

The basic behavior of the simulated glacial meltwater plume is demonstrated in Fig. 3; here, $F / L=10^{-2} \mathrm{~m}^{3} \mathrm{~s}^{-3}$. As in Fig. 2, the initial condition is a uniform stratification of $N=3 \times$ $10^{-3} \mathrm{~s}^{-1}$; this yields $|N / f| \simeq 20$, similar to the meltwater plume simulations of Naveira Garabato et al. (2017). For now, the stratification is implemented through a linear vertical salinity gradient, fixed temperature, and a linear equation of state with haline contraction coefficient $\beta=7.8 \times 10^{-4} \mathrm{psu}^{-1}$ (Vallis 2017). Here and throughout the paper we normalize plotted meltwater distributions to integrate to 1 . Following the evolution of the passive meltwater tracer, we see that the turbulent plume initially rises rapidly, and then moves northward once it reaches neutral buoyancy. The northward flow is deflected to the left by the Coriolis force, resulting in a strong westward jet; this is consistent with the observations and two-dimensional simulations of Naveira Garabato et al. (2017).

Next, we consider the time evolution of the horizontally averaged meltwater distribution over one day of simulation. To quantify the effect that Earth's rotation may play in determining the plume's settling depth (e.g., Fabregat Tomàs et al. 2016; Naveira Garabato et al. 2017), we conduct two simulations: one where the Coriolis parameter $f$ has a realistic value $-1.4 \times 10^{-4} \mathrm{~s}^{-1}$, and one where $f$ has been set to zero. The results of these experiments are shown in Fig. 4. We observe that, for this realistic choice of $|N / f|$, the meltwater's settling depth is largely determined on a time scale $N^{-1}$. As we approach a time scale of 1 day, the mean settling depths in the different simulations diverge slightly: in the rotating case, the meltwater rises on average around $20 \mathrm{~m}$ higher. Additionally, 
A

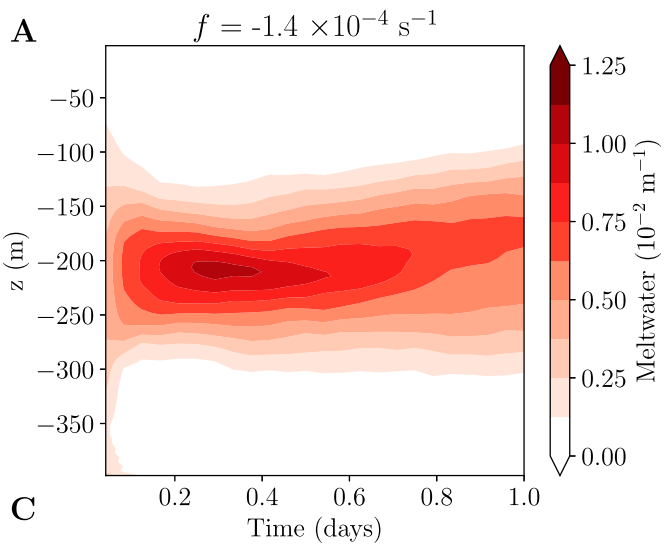

B
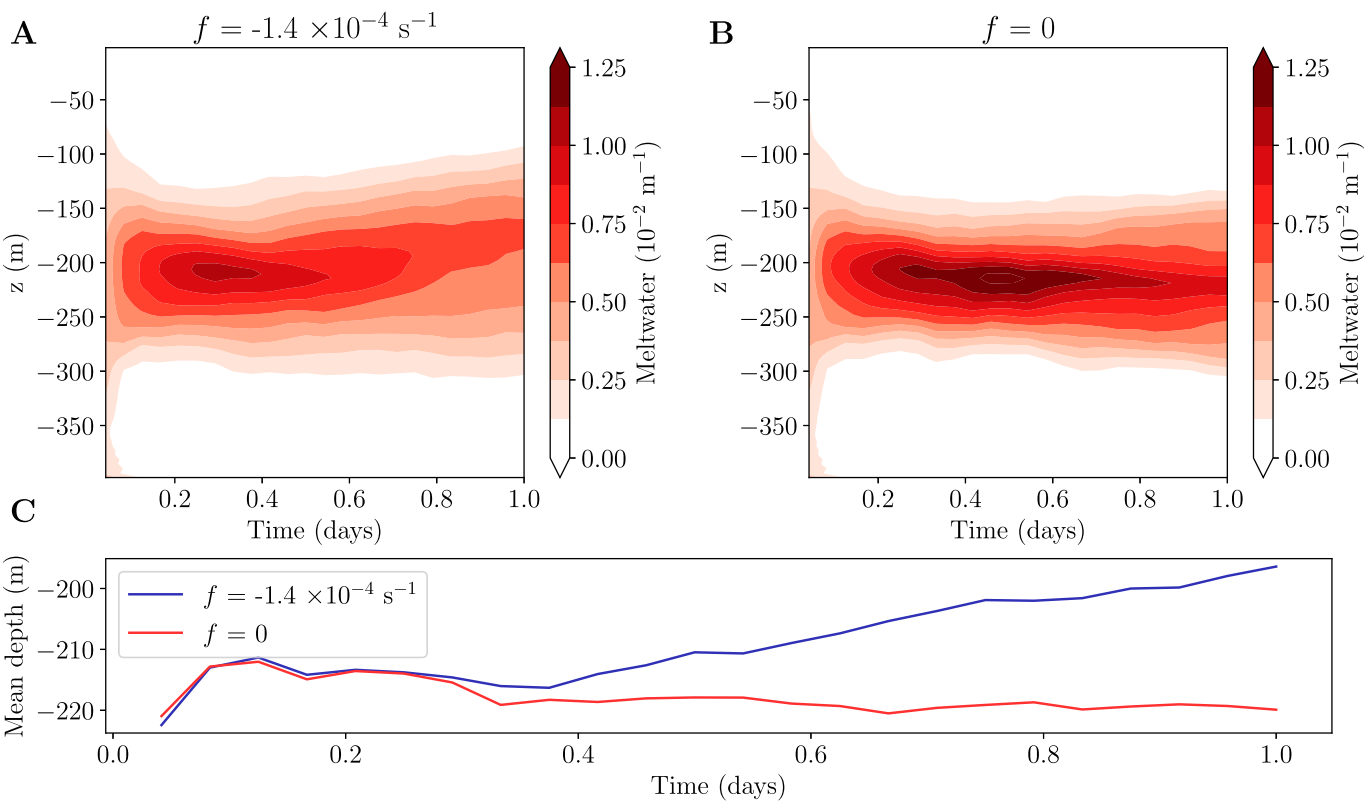

FIG. 4. The evolution of the horizontally averaged vertical meltwater distribution over 1 day of simulation, for a realistic value of the Coriolis parameter $f$ and for a case where $f=0$. (a),(b) The evolution of the distributions and (c) the evolution of the mean settling depth are shown. Here, $F=10 \mathrm{~m}^{4} \mathrm{~s}^{-3}$, and $L=1 \mathrm{~km}$. In our simulations, rotational effects broaden the distribution of meltwater over a wider range of depths. The effect on the mean settling depth is smaller and of the opposite sign as that found by Naveira Garabato et al. (2017); we discuss this in the text.

the rotating experiment also shows a broadening of the vertical meltwater distribution on this time scale, suggestive of rotational effects playing a mixing role.

Interestingly, these results conflict with those of Naveira Garabato et al. (2017), who used two-dimensional simulations to argue that centrifugal instability is a dominant mechanism acting to decrease the meltwater's rise height. As the northward-moving meltwater is deflected to the left by the Coriolis force, a strong zonal jet develops (Fig. 3); centrifugal instability can occur if the resulting anticyclonic vorticity is large enough ( $\zeta / f<-1$; Haine and Marshall 1998), promoting lateral export and mixing of the meltwater. In their two-dimensional simulations, Naveira Garabato et al. (2017), observed over the same timeframe of 1 day that setting $f=-1.4 \times 10^{-4} \mathrm{~s}^{-1}$ was sufficient to deepen the peak of the meltwater distribution by $\sim 50 \mathrm{~m}$ compared to the case with $f=$ 0 , an effect that is absent in Fig. 4. In appendix $\mathrm{C}$ we address this discrepancy using additional two-dimensional simulations: those results suggest that the effect observed in the simulations of Naveira Garabato et al. (2017) may be related to their use of a restoring buoyancy source formulation rather than a constant buoyancy source formulation as implemented in this study.

The effect of rotation on the meltwater settling depth in our simulations is smaller than that found by Naveira Garabato et al. (2017), and has the opposite sign. This effect is relatively unimportant compared to the role played by the buoyancy source per unit width $(F / L)$ and ambient stratification $(N)$ : this can be inferred both from Fig. 2 and the rapid initial stratification-driven adjustment in Fig. 4, and is confirmed in the large-eddy simulations presented in the next section
(Fig. 5). The effect emerges on the same time scale in which the meltwater flow reaches $x=0$ after having reentered from the eastern boundary ( $\sim 1$ day, see Fig. 3 ), and may thus also be a consequence of the idealized nature of the simulation setup. For the purposes of this study, we remain agnostic as to whether this effect represents a physical mechanism operating in the real world, and simply conclude the following. First, for realistic values of $|N / f|$, centrifugal instability is not important in determining the meltwater's settling depth. Second, rotational effects in general play at most a small role in determining the meltwater's settling depth, compared to the role played by $F, L$, and $N$.

\section{b. Vertical meltwater distribution: Uniform stratification}

Now, we can evaluate how the meltwater's settling depth depends on the buoyancy source and the background stratification. We conduct a set of simulations where $F, L$, and $N$ are separately varied: the vertical meltwater distributions after $6 \mathrm{~h}$ of integration are shown in Fig. 5. We choose this time scale because by this point the depth of the meltwater has approximately stabilized (Fig. 4). The default values of $F, L$, and $N$ in Fig. 5 are $10 \mathrm{~m}^{4} \mathrm{~s}^{-3}, 1 \mathrm{~km}$ and $3 \times 10^{-3} \mathrm{~s}^{-1}$. Because $F$ is not necessarily an intuitively accessible quantity, for the case of varying $F$ we included as an additional $x$ axis an approximate lower bound on the corresponding glacial mass loss due to melt (appendix D). On top of the distributions obtained from the simulations we also plot predictions from the simple scaling solution and the one-dimensional line plume model presented above. Both show excellent agreement with the high-resolution simulations, suggesting that they parameterize the settling depth extremely well in these idealized conditions. 

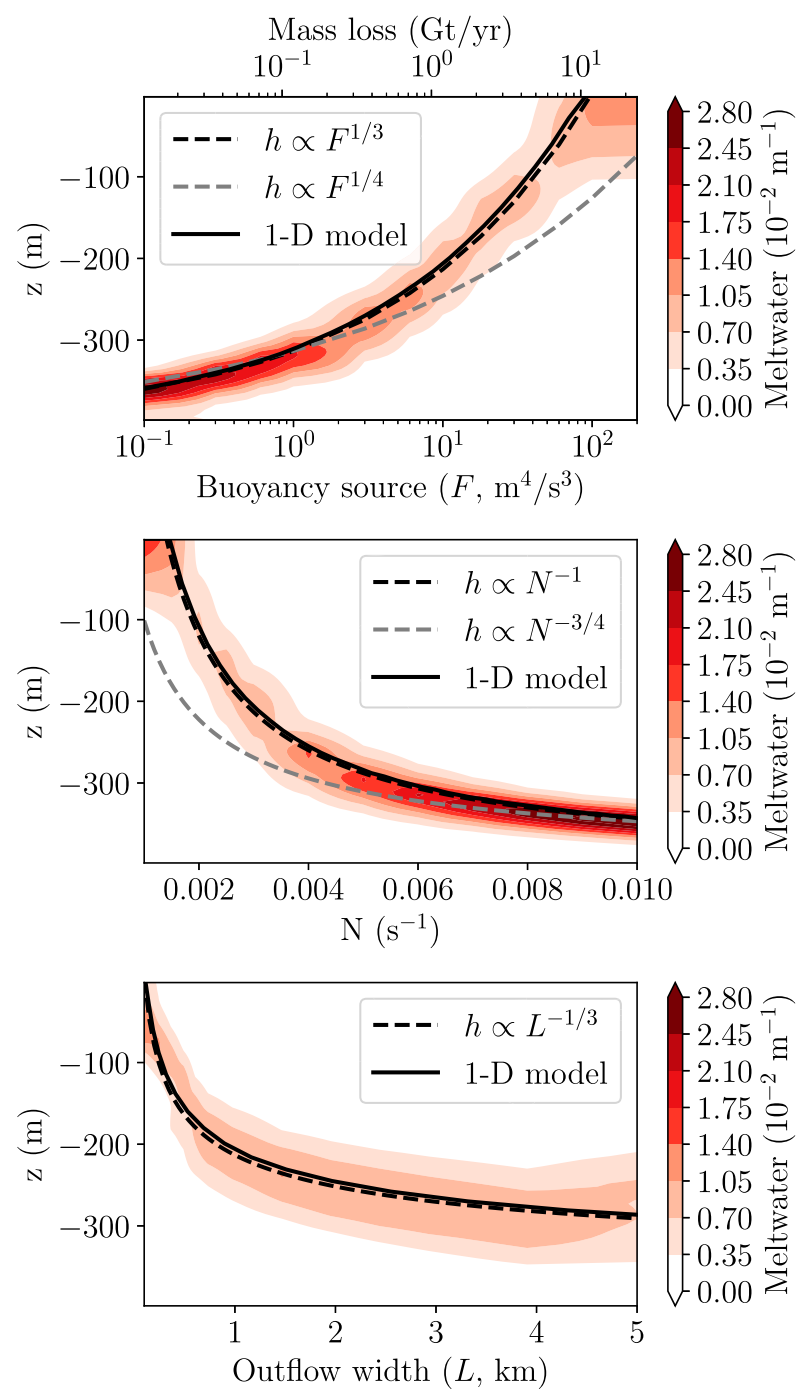

FIG. 5. The horizontally averaged vertical meltwater distribution after $6 \mathrm{~h}$ of simulation, for varying buoyancy source $F$, varying stratification $N$, and varying outflow width $L$. For the case of varying $F$, we have also estimated a lower bound on the corresponding mass loss due to melt (see text). On top of the distributions we plot the settling depths predicted by the simple scaling relationships (dashed) and the one-dimensional line plume model (solid) with $a=2.6$ : both show excellent agreement with the highresolution simulations. The new scaling relationships show substantial improvement over the scaling relationships for point source plumes $\left[h \propto\left(F / N^{3}\right)^{1 / 4}\right]$.

For the scaling solution, we have used $a=2.6$ : the good agreement with the simulation results indicates that the coefficient matches that for point source plumes (Speer and Marshall 1995; Fabregat Tomàs et al. 2016).

\section{c. Vertical meltwater distribution: Nonuniform stratification}

In the real world, the buoyancy frequency $N$ is nonuniform in time and space. For example, observations from Pine Island Bay show that vertical profiles of temperature, salinity, and meltwater fraction display significant interannual variability (Dutrieux et al. 2014b). In Fig. 6 we demonstrate this variability by plotting temperature and salinity profiles collected next to the meltwater outflow from Pine Island Glacier in 2009 and 2014 (Jacobs et al. 2011; Heywood et al. 2016), together with estimates of the corresponding meltwater fractions. Notably, in 2009 meltwater was primarily centered at a depth of $400 \mathrm{~m}$, while in 2014 it was able to rise to the surface. This difference appears too dramatic to be explained purely by interannual variability in meltwater fluxes. For example, because of the $h \propto F^{1 / 3}$ scaling, changing rise height by even a factor of 2 requires $F$ to change by a factor of 8 ; meanwhile, observations indicate that meltwater export from beneath the Pine Island ice shelf has varied by at most by a factor of 3 between years (Dutrieux et al. 2014b). Hence, we propose that the variability in stratification played a major role.

We investigate the effect of the different background conditions in 2009 and 2014 by using the top $400 \mathrm{~m}$ of the observed temperature and salinity profiles as initial conditions in our high-resolution simulations. From these, Oceananigans.jl calculates a density profile using the idealized nonlinear equation of state proposed by Roquet et al. (2015), optimized for near freezing. We consider two different buoyancy sources, $F / L=10^{-3} \mathrm{~m}^{3} \mathrm{~s}^{-3}$ and $F / L=10^{-2} \mathrm{~m}^{3} \mathrm{~s}^{-3}$; these values are chosen specifically to help illustrate the important dynamics. The vertical meltwater distributions after $6 \mathrm{~h}$ are shown in Fig. 7. We additionally plot an estimate of the strength of the initial stratification as a function of depth; this is obtained by calculating $N^{2}=-\left(g / \rho_{0}\right)(d \rho / d z)$ for each vertically adjacent pair of data points and applying a moving average with a $20-\mathrm{m}$ window to identify important trends. For the case of $F / L=$ $10^{-2} \mathrm{~m}^{3} \mathrm{~s}^{-3}$, we see that there is little difference in the vertical meltwater distribution between 2009 and 2014 conditions. However, the simulations with $F / L=10^{-3} \mathrm{~m}^{3} \mathrm{~s}^{-3}$ show a marked difference: in the 2009 case, meltwater settles at $\sim 350$ $\mathrm{m}$ depth, while in the 2014 case it rises around $100 \mathrm{~m}$ further. Finally, we have also plotted the settling depths predicted by the one-dimensional plume model, using the same initial stratification profiles: there is near-perfect agreement with the peaks of the meltwater distributions obtained from our highresolution simulations.

The behavior exhibited in the simulations with $F / L=$ $10^{-3} \mathrm{~m}^{3} \mathrm{~s}^{-3}$ is qualitatively consistent with the observations (Fig. 6): namely, meltwater rose much higher in 2014. The lack of full quantitative agreement is expected, because we have simulated only the top $400 \mathrm{~m}$ of the water column, neglected changes in the sub-ice-shelf meltwater dynamics, and neglected other real-world processes that could affect the settling depth (such as changes in the ambient circulation or wind-driven upwelling). We suggest that the difference in settling depths between our 2009 and 2014 simulations is a consequence of the $N^{2}$ peak at around $350 \mathrm{~m}$ that was present in 2009 but not in 2014: the meltwater was "trapped" by the local maximum in stratification. This illustrates an important point: localized variability in the ambient stratification $N(z)$ can have a substantial effect on meltwater settling depth even when the effective buoyancy flux remains constant. When the buoyancy source is larger $\left(F / L=10^{-2} \mathrm{~m}^{3} \mathrm{~s}^{-3}\right)$, the meltwater can "break 

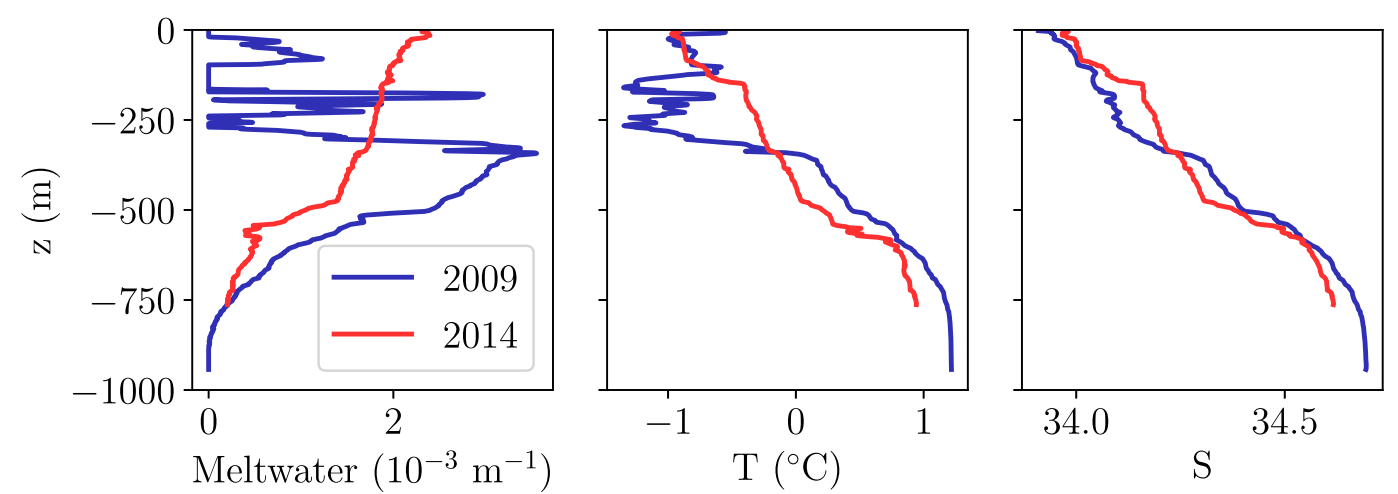

FIG. 6. Observed 2009 and 2014 temperature and salinity profiles next to the meltwater outflow from Pine Island Glacier, as well as estimated meltwater fractions. In 2009, meltwater was primarily centered at a 400-m depth, while in 2014 it was able to rise to the surface.

through" the stratification maximum, and ends up with a vertical distribution very similar to the corresponding 2014 stratification profile.

\section{Discussion}

The potency of Antarctic glacial meltwater as a driver of regional and global climate trends likely depends strongly on its settling depth or vertical distribution after exiting the ice shelf cavity. Specifically, it seems feasible that meltwater could only explain the signs of the observed Southern Ocean trends (surface cooling, surface freshening, and sea ice expansion) as long as it rises close enough to the surface to shoal the mixed layer base and to yield a measurable surface salinity anomaly. Pauling et al. (2016), who considered the effects of releasing freshwater at different depths, found that the depth of meltwater release had no significant effect on the magnitude of sea ice expansion. However, they also found a much weaker response of sea ice expansion to freshwater forcing than other studies (Bintanja et al. 2013, 2015; Rye et al. 2020); these intermodel differences deserve further study. Observational data (e.g., Loose et al. 2009; Dutrieux et al. 2014b; Kim et al. 2016;
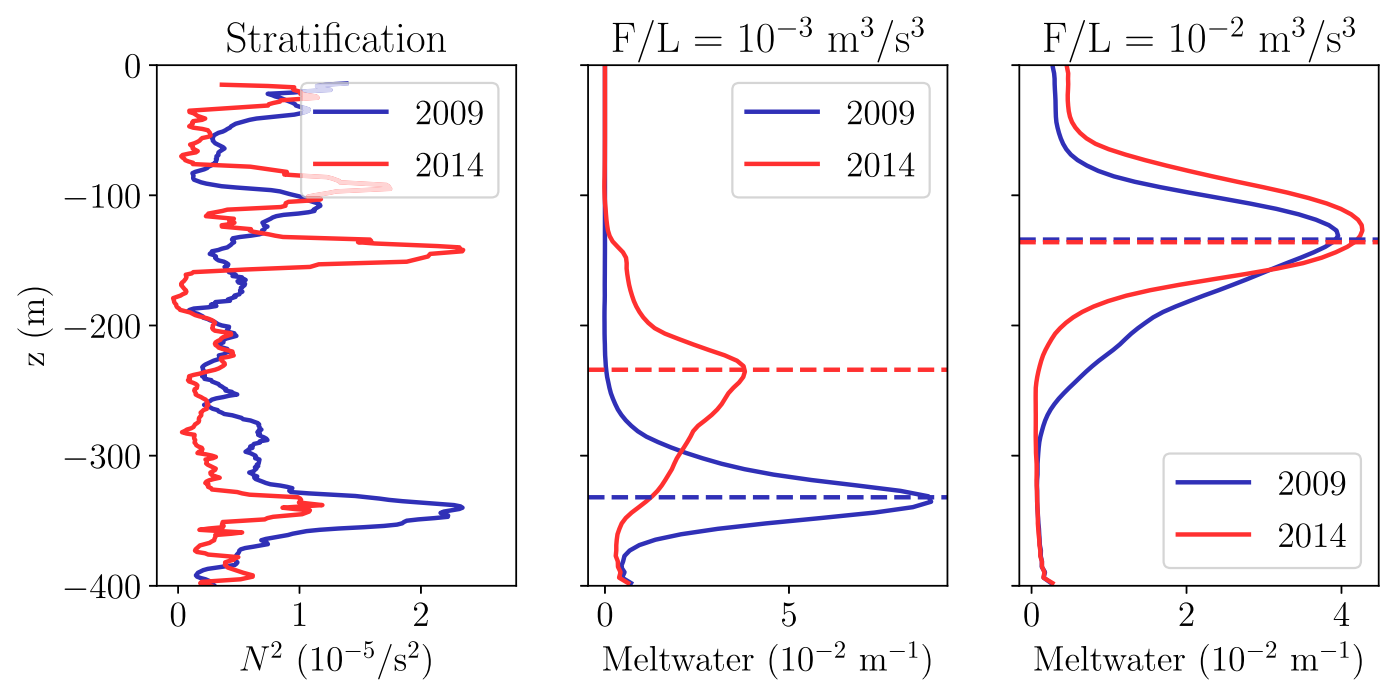

FIG. 7. Simulated vertical meltwater distributions (from LES, solid) for $F / L=10^{-3} \mathrm{~m}^{3} \mathrm{~s}^{-3}$ and $F / L=10^{-2} \mathrm{~m}^{3} \mathrm{~s}^{-3}$, with initial conditions set by observed temperature and salinity profiles for 2009 and 2014 . Horizontal dashed lines indicate the settling depths predicted by the one-dimensional line plume model for the same conditions; notably, the line plume model accurately predicts the peak of the simulated meltwater distribution in all cases. We also plot depth profiles of stratification strength in terms of $N^{2}$ (see text). For $F / L=10^{-2} \mathrm{~m}^{3} \mathrm{~s}^{-3}$ we see that there is little difference in the vertical meltwater distribution between 2009 and 2014 conditions. However, the simulations with $F / L=10^{-3} \mathrm{~m}^{3} \mathrm{~s}^{-3}$ show a marked difference: the qualitative trend is consistent with observations (Fig. 6). Here, we propose that the rising meltwater was "trapped" by the notable local stratification maximum at around 350-m depth in the 2009 conditions. 
Naveira Garabato et al. 2017; Biddle et al. 2019) highlight that meltwater can settle at a range of depths in the subpolar sea, suggesting that time-varying environmental conditions and the properties of individual meltwater plumes play important roles in determining the vertical distribution of meltwater in the shelf seas, and therefore the climate impact of meltwater anomaly production.

In Fig. 8, we identify two different paradigms for introducing Antarctic meltwater fluxes into simulations of global climate. In paradigm $\mathrm{A}$, meltwater fluxes (from observations or melt rate models) are inserted into the ocean model at some fixed vertical level. This paradigm has dominated the literature: as described earlier, most climate modeling studies have introduced all of the meltwater flux at the surface. In other studies, the meltwater has been uniformly distributed over a fixed range of depths below the ice shelf front (Beckmann and Goosse 2003; Mathiot et al. 2017). Given the likely climatic importance of Antarctic glacial meltwater, the strong dependence of settling depth on buoyancy release (e.g., as explored in this study), and the vast heterogeneity in the observed mass loss rates and ambient conditions at different ice shelves (Rignot et al. 2019), any such "one size fits all"' solution risks missing substantial aspects of the climate response to Antarctic mass loss. However, an alternative approach is possible: in paradigm $B$, the melt rate model is coupled to a dynamic plume model that describes the small-scale dynamics of buoyant meltwater plumes and accurately calculates the vertical distribution of meltwater. The meltwater is then inserted into the ocean model in accordance with this distribution.

Parameterizing the depth of meltwater input into general circulation models using buoyant plume theory is not a new idea: Cowton et al. (2015) have employed this technique to conduct more efficient simulations of Arctic glacial fjords. Because Arctic tidewater glaciers are essentially vertical for the entire depth of the water column, a single one-dimensional plume model can be used to calculate both melt rates and plume dynamics. However, this is not true in the context of Antarctic ice shelves, in part because of the large discontinuity in slope that occurs at the base of the ice-shelf front. Therefore, a number of issues remain to be solved before paradigm $\mathrm{B}$ could be implemented in simulations of global climate.

In this study we have shown that the settling depth of the meltwater after its escape from beneath the ice shelf is well described by one-dimensional plume theory even for complex nonuniform stratification (Fig. 7), however, the critical input parameter $F / L$ remains a function of complex sub-ice-shelf processes. If the "melt rate model" in Fig. 8 is a box model (Olbers and Hellmer 2010; Reese et al. 2018), $F$ could be estimated from the properties of the outflow from the box closest to the ice-shelf front. If it is a plume model (MacAyeal 1985; Jenkins 2011; Lazeroms et al. 2018; Pelle et al. 2019), F could be estimated from the remaining buoyancy flux at the ice-shelf front. However, both types of models may have issues calculating $L$, because they do not resolve gyre circulations below the ice shelf (Grosfeld et al. 1997; Losch 2008; De Rydt et al. 2014),

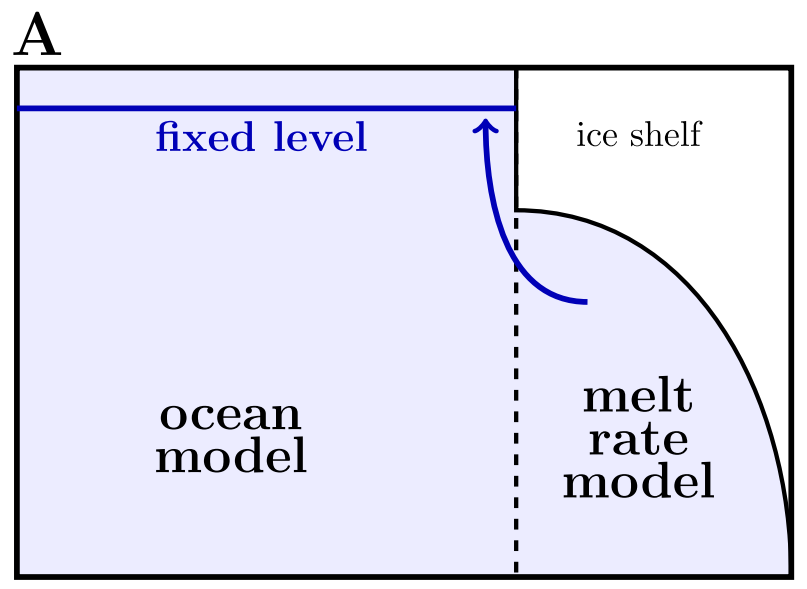

\section{B}



FIG. 8. Schematic describing two different paradigms for Antarctic meltwater fluxes in simulations of global climate. In paradigm A, the fluxes from a melt rate model are inserted into the ocean model at some fixed vertical level; this approach has dominated the literature. In paradigm $\mathrm{B}$, the melt rate model is coupled to a dynamic plume model that describes the smallscale dynamics of buoyant meltwater plumes and accurately calculates the vertical distribution of meltwater for insertion into the ocean model. Given the potential climatic importance of glacial meltwater, the strong dependence of settling depth on the buoyancy forcing, and the vast heterogeneity in the observed mass loss rates and ambient conditions at different ice shelves, this approach would likely represent a significant improvement over the one-size-fits-all approach of paradigm A.

and the focusing of meltwater outflows by kilometer-scale channels at the base of the ice (Dutrieux et al. 2013, 2014a; Naveira Garabato et al. 2017).

Finally, one-dimensional plume models have fundamental limitations even in the relatively simple case of a plume rising next to a vertical wall. For example, this neglects the alongshelf dynamics, which affect the plume's location and width as well the relevant ice shelf front depth, and have been shown to significantly affect total melt rates in the Arctic context (Jackson et al. 2020). However, the most significant limitation of using one-dimensional plume models to compute meltwater 
A

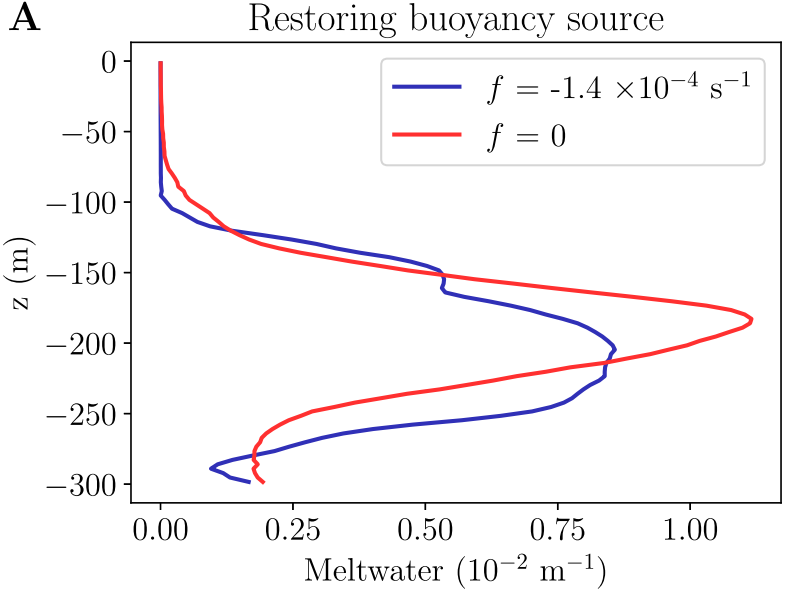

B

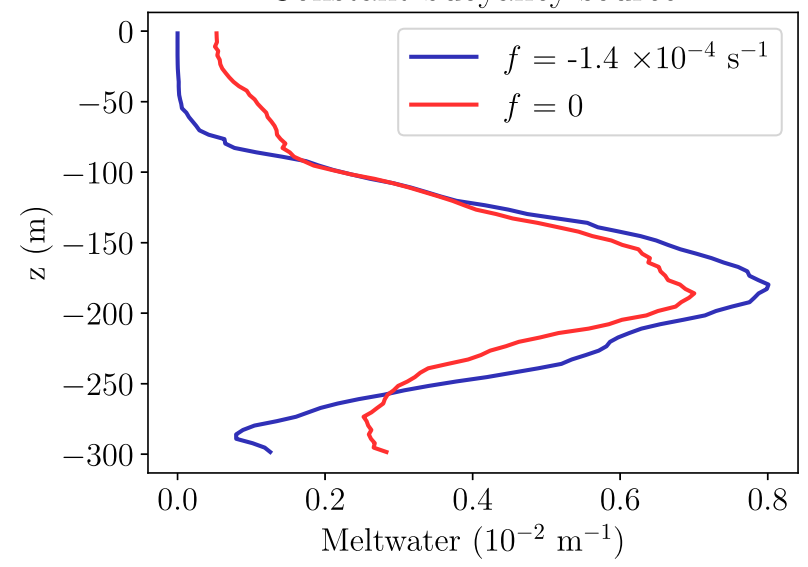

FIG. 9. Vertical meltwater distributions, for rotating and nonrotating cases, in a two-dimensional domain. We have introduced meltwater via (a) a restoring buoyancy source (following Naveira Garabato et al. 2017; see text), and (b) a constant buoyancy source (as in the simulations described in the main text). When a constant buoyancy source is employed, the peak of the vertical distribution is not noticeably influenced by the effects of rotation. However, when a restoring buoyancy source is employed, rotation deepens the peak by $\sim 50 \mathrm{~m}$, consistent with the simulations of Naveira Garabato et al. (2017). Since the magnitude of the buoyancy source is a primary control on the meltwater's settling depth, the importance of any other parameters can only be accurately investigated by holding the buoyancy source constant; therefore, these results show that the use of restoring nonconstant buoyancy sources may exaggerate the effect of rotation on the settling depth.

settling depths is that these one-dimensional parameterizations can only output a single meltwater settling depth $[B(z)=0]$. Meanwhile, observed vertical meltwater distributions can have complex, possibly multimodal shapes. Short of explicitly resolving the small-scale fluid dynamics of the meltwater plume next to and below the entire ice shelf, it may be possible to extend upon the one-dimensional plume model, perhaps by introducing a time dependence, to explicitly include a passive meltwater tracer that would allow for the calculation of a vertical distribution rather than just its peak.

\section{Conclusions}

Antarctic glacial meltwater is likely an important driver of observed Southern Ocean climate trends (Bintanja et al. 2013; Rye et al. 2014; Bintanja et al. 2015; Rye et al. 2020), and will have a significant impact throughout the twenty-first century (Bronselaer et al. 2018; Golledge et al. 2019). Nevertheless, the factors determining the vertical distribution of meltwater in the water column remain poorly understood. Here, we have used a hierarchy of approaches, spanning simple scaling laws to highresolution large-eddy simulations of the meltwater outflow from beneath an ice shelf, to gain a fundamental understanding of the most important controls on the meltwater's settling depth. We found that the settling depth is primarily a function of the buoyancy forcing per unit width and the ambient stratification, consistent with the classical theory of turbulent buoyant plumes and in contrast to previous suggestions that centrifugal instability plays an important role (Naveira Garabato et al. 2017). Our simulations also provide insight into the observed interannual variability in meltwater settling depth, using Pine Island Glacier as an example; the role of the nonuniform background stratification is highlighted. We expect that the results of this study are relevant to a wide range of Antarctic ice shelves, in part because the focusing of sub-ice-shelf meltwater into a narrow outflow is a fundamental consequence of a generic sub-ice-shelf circulation (Grosfeld et al. 1997; Losch 2008; De Rydt et al. 2014). The work presented in this study is a first step toward a dynamic parameterization of Antarctic meltwater settling depth for simulations of global climate. Because of the likely climatic importance of Antarctic glacial meltwater, the strong dependence of mass loss rates on buoyancy forcing, and the vast heterogeneity in the observed mass loss rates and ambient conditions at different ice shelves, such a parameterization could be crucial for the accurate simulation and forecasting of high-latitude climate in a warming world.

Acknowledgments. We thank Alberto Naveira Garabato for discussions that helped motivate this work, Gianluca Meneghello and Jean-Michel Campin for discussions that aided in its execution, and two reviewers for comments that greatly improved the manuscript. J. M. and C. D. R. acknowledge support from the NASA MAP program and the MIT-GISS cooperative agreement. A. R. was supported through the CliMA initiative funded by the Eric and Wendy Schmidt foundation. P. D. was supported by NSF OPP Award 1643285 and his Center for Climate and Life Fellowship from the Earth Institute of Columbia University.

Data availability statement. This study generated no new data. Code for the one-dimensional line plume model and the two- and three-dimensional large-eddy simulations is available at https://github.com/arnscheidt/antarctic-meltwatersettling-depth. 


\section{APPENDIX A}

\section{One-Dimensional Line Plume Model}

We construct a one-dimensional vertical line plume model in the spirit of Morton et al. (1956). Here, the rate of turbulent entrainment of ambient fluid into the rising buoyant plume is parameterized as proportional to the plume's vertical velocity via an entrainment coefficient $\alpha$. We assume that the vertical velocity $w$ is uniform within the plume and zero outside, and that the plume is rising next to a wall (so that entrainment can only occur from one side). We can then write down volume, momentum, and mass conservation equations within the plume:

$$
\begin{aligned}
\frac{d}{d z}(D w) & =\alpha w, \\
\frac{d}{d z}(D w \rho w) & =D g\left(\rho_{a}-\rho\right), \\
\frac{d}{d z}(D w \rho) & =\alpha w \rho_{a} .
\end{aligned}
$$

Here, $\rho(z)$ is the density of the plume, $\rho_{a}(z)$ is the ambient density, $D$ is the width of the plume perpendicular to the wall, and $\alpha$ is the entrainment coefficient. Assuming that $\rho(z)$ differs only slightly from the reference density $\rho_{0}$, we can rewrite Eq. (A2) as

$$
\frac{d}{d z}\left(D w^{2}\right)=D \frac{g}{\rho_{0}}\left(\rho_{a}-\rho\right)
$$

Following the reasoning in Morton et al. (1956), we can use Eq. (A1) to rewrite Eq. (A3) as

$$
\frac{d}{d z}(D w \rho)=\rho_{a} \frac{d}{d z}(D w)=\frac{d}{d z}\left(D w \rho_{a}\right)-D w \frac{d}{d z} \rho_{a},
$$

such that

$$
\frac{d}{d z}\left[D w\left(\rho_{a}-\rho\right)\right]=D w \frac{d \rho_{a}}{d z}
$$

Now, writing $D w=Q$ (volume flux), $D w^{2}=M$ (momentum flux), and $D w g\left[\left(\rho_{a}-\rho\right) / \rho_{0}\right]=B$ (buoyancy flux), we obtain the three coupled ODEs

$$
\begin{aligned}
& \frac{d Q}{d z}=\alpha \frac{M}{Q}, \\
& \frac{d M}{d z}=\frac{Q B}{M}, \\
& \frac{d B}{d z}=Q \frac{g}{\rho_{0}} \frac{d \rho_{a}}{d z}=-Q N^{2} .
\end{aligned}
$$

These equations are similar but not equivalent to the corresponding equations for point plumes. Furthermore, each of the three governing equations has implicitly been divided by a factor of $L$ ( $x$ width of the plume); thus, all of the quantities $Q$, $M, B$ are fluxes per unit width.

\section{APPENDIX B}

\section{Buoyancy Source Implementation}

We implement the buoyancy source $F\left(\mathrm{~m}^{4} \mathrm{~s}^{-3}\right)$ in our highresolution simulations as a volume-conserving "virtual salinity flux" (Huang 1993). The conservation law for an arbitrary tracer $c$ in Oceananigans.jl is

$$
\frac{\partial c}{\partial t}+\mathbf{u} \cdot \nabla c=-\nabla \cdot \mathbf{q}_{c}+F_{c},
$$

where $\mathbf{q}_{c}$ is a diffusive flux and $F_{c}$ is an external source term. In our simulations, we introduce the buoyancy uniformly across a volume that extends width $L$ in the $x$ direction, 10 grid cells in the $y$ direction $(\sim 100 \mathrm{~m})$, and one grid cell in the $z$ direction $(\sim 4 \mathrm{~m})$. The width of $100 \mathrm{~m}$ in the $y$ direction is chosen in part to simulate the fact that the plume has nonzero horizontal momentum when emerging from beneath the ice shelf, while still remaining consistent with observations and prior simulations of this scenario (Naveira Garabato et al. 2017). Including this initial velocity explicitly would impact the effect of the Coriolis force on the dynamics (e.g., strengthening the jet in Fig. 3), but it is unclear to what extent this would affect the meltwater settling depth; we leave this as a question for future work. Defining the buoyancy source volume as $V_{b}$, we can write

$$
\int_{V_{b}} d V \frac{d b}{d t} \text { source }=F
$$

where $d b / d t_{\text {source }}$ refers only to the term within the full buoyancy conservation equation that comes from the external buoyancy source. Now, recall that

$$
b=-\frac{g}{\rho_{0}}\left(\rho-\rho_{0}\right)
$$

and that, to first order,

$$
\rho=\rho_{0}\left[1-\alpha\left(T-T_{0}\right)+\beta\left(S-S_{0}\right)\right] .
$$

Thus, if no temperature forcing is introduced,

$$
\frac{d b}{d t}_{\text {source }}=\frac{d b}{d \rho} \frac{d \rho}{d t_{\text {source }}}=-\frac{g}{\rho_{0}}{\frac{d \rho}{d t_{\text {source }}}}=-g \beta \frac{d S}{d t} \text { source }
$$

and, by (B2):

$$
F=-\int_{V_{b}} d V g \beta \frac{d S}{d t}_{\text {source }} \equiv-g \beta F_{S}
$$

where $F_{S}$ is the volume-integrated salinity flux (psu $\left.\mathrm{m}^{3} \mathrm{~s}^{-1}\right)$. For a chosen $F$ we therefore obtain a corresponding $F_{S}$ by (B6). Then, in our simulations, we distribute $F_{S}$ uniformly across $V_{b}$.

\section{APPENDIX C}

\section{Restoring Buoyancy Sources May Exaggerate the Importance of Rotational Effects in Determining the Meltwater's Settling Depth}

Our results conflict with those of Naveira Garabato et al. (2017). Using a two-dimensional model, they found that including 
realistic rotation deepened the peak of the observed meltwater distribution by $\sim 50 \mathrm{~m}$ compared to a nonrotating case, after one day of integration. To clarify why there is a discrepancy, we conduct additional two-dimensional simulations with Oceananigans.jl that are designed to closely replicate those of Naveira Garabato et al. (2017).

The model domain spans $5 \mathrm{~km} \times 300 \mathrm{~m}$ and is zonally reentrant. Our resolution is $512 \times 96$, i.e., $\sim 10 \mathrm{~m} \times 3 \mathrm{~m}$. The initial stable stratification is implemented using a linear equation of state and a linear temperature gradient from $1^{\circ} \mathrm{C}$ at the bottom to $3^{\circ} \mathrm{C}$ at the top. At the northern boundary, we continuously relax back to the stable initial condition. At the base of the southern boundary we introduce meltwater via an unstable restoring region that extends $160 \mathrm{~m}$ in the $y$ direction. In the unstable restoring region, temperature is relaxed to a temperature $T_{r}(y)$, which is set following a linear gradient: its value is $2^{\circ} \mathrm{C}$ at $y=0 \mathrm{~m}$ and $1^{\circ} \mathrm{C}$ at $y=160 \mathrm{~m}$. For clarity, in the buoyancy source region:

$$
\frac{d T}{d t}=(\text { other terms })+\lambda\left[T_{r}(y)-T\right]
$$

where $\lambda=1 / 20 \mathrm{~s}^{-1}$. This experiment is conducted twice, once with $f=-1.4 \times 10^{-4} \mathrm{~s}^{-1}$ (realistic rotation) and once with $f=0$ (no rotation). We then conduct an additional set of simulations using a constant buoyancy source, which is set to approximately yield the same settling depth.

Figure 9 shows the vertical distribution of glacial melt in the water column after 1 day, for both rotating and nonrotating cases, and for a restoring formulation and a constant buoyancy source formulation. When a restoring formulation is used, in the rotating case the peak is $\sim 50 \mathrm{~m}$ deeper than in the nonrotating case, consistent with the results of Naveira Garabato et al. (2017). However, when a constant buoyancy source is used, rotation appears to have no effect on the peak of the meltwater distribution. Since the magnitude of the buoyancy source is a primary control on the meltwater's settling depth, the importance of any other parameters can only be accurately investigated by holding the buoyancy source constant. This suggests that the bottom results in Fig. 9 are more physical, and that the use of restoring nonconstant buoyancy sources may exaggerate the effect of rotation on the settling depth.

\section{APPENDIX D}

\section{Approximate Lower Bound on Net Melting Corresponding to a Given Buoyancy Source}

For the second $x$ axis included in Fig. 5a, we estimate a lower bound on the glacial mass loss due to melt (i.e., net melting) corresponding to a buoyancy source $F\left(\mathrm{~m}^{4} \mathrm{~s}^{-3}\right)$. In the real world, melting is spatially distributed throughout the ice-shelf cavity, and the meltwater that is released loses buoyancy as it ascends toward the ice-shelf front. If the meltwater plume carries a buoyancy flux $F$ by the time it reaches the base of the ice shelf (i.e., the base of our model domain), the smallest possible rate of mass loss that could be responsible for that buoyancy flux would be achieved if all the melting had occurred at precisely that depth.
To obtain a lower bound on the mass loss corresponding to a given $F$, therefore, let us assume that $F$ arises entirely from melting occurring at the base of our model domain (i.e., the base of the ice-shelf front). If this represents pure freshwater, the buoyancy gained by its input into the system is equivalent to the buoyancy gained by removing the same volume of water at the ambient salinity $S_{0}$ (set to $34.6 \mathrm{psu}$ ). This can be justified rigorously by noting that, if we add a small volume of water $\Delta V$ with salinity 0 to a large volume of water $V$ with salinity $S_{0}$, the new salinity is given by

$$
S_{0}+\Delta S=\frac{V S_{0}}{V+\Delta V} \simeq S_{0}\left(1-\frac{\Delta V}{V}\right),
$$

i.e.,

$$
V \Delta S \simeq-S_{0} \Delta V
$$

Moving from volumes to fluxes, let $F_{M}$ denote our lower bound on the mass flux $\left(\mathrm{kg} \mathrm{s}^{-1}\right)$. Following (D2), the volumeintegrated virtual salinity flux $F_{S}\left(\mathrm{psu} \mathrm{m}^{3} \mathrm{~s}^{-1}\right)$ is given by

$$
F_{S} \simeq-S_{0} \frac{F_{M}}{\rho_{0}} .
$$

Using (B6), we find that

$$
F_{M} \simeq \frac{\rho_{0} F}{g \beta S_{0}}
$$

where $F$ is the buoyancy flux $\left(\mathrm{m}^{4} \mathrm{~s}^{-3}\right)$.

A complementary interpretation of $F_{M}$ is the following: for a mass loss flux of $F_{M}$, the meltwater may rise no higher than the settling depth shown in Fig. 5.

\section{REFERENCES}

Beckmann, A., and H. Goosse, 2003: A parameterization of ice shelf-ocean interaction for climate models. Ocean Modell., 5 , 157-170, https://doi.org/10.1016/S1463-5003(02)00019-7.

Bezanson, J., A. Edelman, S. Karpinski, and V. B. Shah, 2017: Julia: A fresh approach to numerical computing. SIAM Rev., 59, 65-98, https://doi.org/10.1137/141000671.

Biddle, L. C., B. Loose, and K. J. Heywood, 2019: Upper ocean distribution of glacial meltwater in the Amundsen Sea, Antarctica. J. Geophys. Res. Oceans, 124, 6854-6870, https:// doi.org/10.1029/2019JC015133.

Bintanja, R., G. Van Oldenborgh, S. Drijfhout, B. Wouters, and C. Katsman, 2013: Important role for ocean warming and increased ice-shelf melt in Antarctic sea-ice expansion. Nat. Geosci., 6, 376-379, https://doi.org/10.1038/ngeo1767.

, - — , and C. Katsman, 2015: The effect of increased fresh water from Antarctic ice shelves on future trends in Antarctic sea ice. Ann. Glaciol., 56, 120-126, https://doi.org/10.3189/ 2015AoG69A001.

Bronselaer, B., M. Winton, S. M. Griffies, W. J. Hurlin, K. B. Rodgers, O. V. Sergienko, R. J. Stouffer, and J. L. Russell, 2018: Change in future climate due to Antarctic meltwater. Nature, 564, 53-58, https://doi.org/10.1038/s41586-018-0712-z.

Carroll, D., D. A. Sutherland, E. L. Shroyer, J. D. Nash, G. A. Catania, and L. A. Stearns, 2015: Modeling turbulent subglacial meltwater plumes: Implications for fjord-scale 
buoyancy-driven circulation. J. Phys. Oceanogr., 45, 2169-2185, https://doi.org/10.1175/JPO-D-15-0033.1.

Cowton, T., D. Slater, A. Sole, D. Goldberg, and P. Nienow, 2015: Modeling the impact of glacial runoff on fjord circulation and submarine melt rate using a new subgrid-scale parameterization for glacial plumes. J. Geophys. Res. Oceans, 120, 796-812, https://doi.org/10.1002/2014JC010324.

De Rydt, J., P. Holland, P. Dutrieux, and A. Jenkins, 2014: Geometric and oceanographic controls on melting beneath Pine Island Glacier. J. Geophys. Res. Oceans, 119, 2420-2438, https://doi.org/10.1002/2013JC009513.

Dutrieux, P., D. G. Vaughan, H. F. Corr, A. Jenkins, P. R. Holland, I. Joughin, and A. Fleming, 2013: Pine Island glacier ice shelf melt distributed at kilometre scales. Cryosphere, 7, 1543-1555, https://doi.org/10.5194/tc-7-1543-2013.

—, C. Stewart, A. Jenkins, K. W. Nicholls, H. F. Corr, E. Rignot, and K. Steffen, 2014a: Basal terraces on melting ice shelves. Geophys. Res. Lett., 41, 5506-5513, https://doi.org/10.1002/ 2014GL060618.

— shelf melting to climatic variability. Science, 343, 174-178, https://doi.org/10.1126/science.1244341.

Ezhova, E., C. Cenedese, and L. Brandt, 2018: Dynamics of threedimensional turbulent wall plumes and implications for estimates of submarine glacier melting. J. Phys. Oceanogr., 48, 1941-1950, https://doi.org/10.1175/JPO-D-17-0194.1.

Fabregat Tomàs, A., A. C. Poje, T. M. Özgökmen, and W. K. Dewar, 2016: Effects of rotation on turbulent buoyant plumes in stratified environments. J. Geophys. Res. Oceans, 121, 5397-5417, https://doi.org/10.1002/2016JC011737.

Golledge, N. R., E. D. Keller, N. Gomez, K. A. Naughten, J. Bernales, L. D. Trusel, and T. L. Edwards, 2019: Global environmental consequences of twenty-first-century ice-sheet melt. Nature, $\mathbf{5 6 6}$, 65-72, https://doi.org/10.1038/s41586-019-0889-9.

Gourmelen, N., and Coauthors, 2017: Channelized melting drives thinning under a rapidly melting Antarctic ice shelf. Geophys. Res. Lett., 44, 9796-9804, https://doi.org/10.1002/2017GL074929.

Grosfeld, K., R. Gerdes, and J. Determann, 1997: Thermohaline circulation and interaction between ice shelf cavities and the adjacent open ocean. J. Geophys. Res., 102, 15 595-15610, https://doi.org/10.1029/97JC00891.

Haine, T. W., and J. Marshall, 1998: Gravitational, symmetric, and baroclinic instability of the ocean mixed layer. J. Phys. Oceanogr., 28, 634-658, https://doi.org/10.1175/ 1520-0485(1998)028<0634:GSABIO > 2.0.CO;2.

Hansen, J., and Coauthors, 2016: Ice melt, sea level rise and superstorms: Evidence from paleoclimate data, climate modeling, and modern observations that $2^{\circ} \mathrm{C}$ global warming is highly dangerous. Atmos. Chem. Phys., 16, 3761-3812, https:// doi.org/10.5194/acp-16-3761-2016.

Helfrich, K. R., and T. M. Battisti, 1991: Experiments on baroclinic vortex shedding from hydrothermal plumes. J. Geophys. Res., 96, 12 511-12 518, https://doi.org/10.1029/90JC02643.

Heywood, K. J., and Coauthors, 2016: Between the devil and the deep blue sea: The role of the Amundsen Sea continental shelf in exchanges between ocean and ice shelves. Oceanography, 29, 118-129, https://doi.org/10.5670/oceanog.2016.104.

Holland, P. R., D. L. Feltham, and A. Jenkins, 2007: Ice shelf water plume flow beneath Filchner-Ronne Ice Shelf, Antarctica. J. Geophys. Res., 112, C05044, https://doi.org/10.1029/ 2006JC003915.

Huang, R. X., 1993: Real freshwater flux as a natural boundary condition for the salinity balance and thermohaline circulation forced by evaporation and precipitation. J. Phys. Oceanogr., 23, 2428-2446, https://doi.org/10.1175/1520-0485(1993)023<2428: RFFAAN $>2.0 . \mathrm{CO} ; 2$.

Jackson, R., and Coauthors, 2020: Meltwater intrusions reveal mechanisms for rapid submarine melt at a tidewater glacier. Geophys. Res. Lett., 47, e2019GL085335, https://doi.org/10.1029/ 2019GL085335.

Jacobs, S. S., A. Jenkins, C. F. Giulivi, and P. Dutrieux, 2011: Stronger ocean circulation and increased melting under Pine Island Glacier ice shelf. Nat. Geosci., 4, 519-523, https:// doi.org/10.1038/ngeo1188.

Jenkins, A., 1991: A one-dimensional model of ice shelf-ocean interaction.J. Geophys. Res., 96, 20 671-20 677, https://doi.org/ 10.1029/91JC01842.

, 2011: Convection-driven melting near the grounding lines of ice shelves and tidewater glaciers. J. Phys. Oceanogr., 41, 2279-2294, https://doi.org/10.1175/JPO-D-11-03.1.

— P. Dutrieux, S. S. Jacobs, S. D. McPhail, J. R. Perrett, A. T. Webb, and D. White, 2010: Observations beneath Pine Island Glacier in West Antarctica and implications for its retreat. Nat. Geosci., 3, 468-472, https://doi.org/10.1038/ngeo890.

Jiang, H., and J. A. Breier, 2014: Physical controls on mixing and transport within rising submarine hydrothermal plumes: A numerical simulation study. Deep-Sea Res. I, 92, 41-55, https:// doi.org/10.1016/j.dsr.2014.06.006.

Jones, J. M., and Coauthors, 2016: Assessing recent trends in highlatitude Southern Hemisphere surface climate. Nat. Climate Change, 6, 917-926, https://doi.org/10.1038/nclimate3103.

Kim, I., D. Hahm, T. S. Rhee, T. W. Kim, C.-S. Kim, and S. Lee, 2016: The distribution of glacial meltwater in the Amundsen Sea, Antarctica, revealed by dissolved helium and neon. J. Geophys. Res. Oceans, 121, 1654-1666, https://doi.org/ 10.1002/2015JC011211.

Kimura, S., P. R. Holland, A. Jenkins, and M. Piggott, 2014: The effect of meltwater plumes on the melting of a vertical glacier face. J. Phys. Oceanogr., 44, 3099-3117, https://doi.org/10.1175/ JPO-D-13-0219.1.

Kostov, Y., D. Ferreira, K. C. Armour, and J. Marshall, 2018: Contributions of greenhouse gas forcing and the southern annular mode to historical southern ocean surface temperature trends. Geophys. Res. Lett., 45, 1086-1097, https://doi.org/ 10.1002/2017GL074964.

Lavelle, J., 1995: The initial rise of a hydrothermal plume from a line segment source-Results from a three-dimensional numerical model. Geophys. Res. Lett., 22, 159-162, https:// doi.org/10.1029/94GL01463.

Lazeroms, W., A. Jenkins, H. Gudmundsson, and R. van de Wal, 2018: Modelling present-day basal melt rates for Antarctic ice shelves using a parametrization of buoyant meltwater plumes. Cryosphere, 12, 49-70, https://doi.org/10.5194/tc-12-49-2018.

Loose, B., P. Schlosser, W. Smethie, and S. Jacobs, 2009: An optimized estimate of glacial melt from the Ross Ice Shelf using noble gases, stable isotopes, and CFC transient tracers. J. Geophys. Res., 114, C08007, https://doi.org/10.1029/2008JC005048.

Losch, M., 2008: Modeling ice shelf cavities in a z-coordinate ocean general circulation model. J. Geophys. Res., 113, C08043, https://doi.org/10.1029/2007JC004368.

MacAyeal, D. R., 1985: Evolution of tidally triggered meltwater plumes below ice shelves. Oceanology of the Antarctic Continental Shelf, S. S. Jacobs, Ed., Antarctic Research Series, Vol. 43, Amer. Geophys. Union, 133-143, https://doi.org/10.1029/AR043p0133.

Marshall, J., A. Adcroft, C. Hill, L. Perelman, and C. Heisey, 1997: A finite-volume, incompressible Navier Stokes model for 
studies of the ocean on parallel computers. J. Geophys. Res., 102, 5753-5766, https://doi.org/10.1029/96JC02775.

Mathiot, P., A. Jenkins, C. Harris, and G. Madec, 2017: Explicit representation and parametrised impacts of under ice shelf seas in the $z^{*}$ coordinate ocean model NEMO 3.6. Geosci. Model Dev., 10, 2849-2874, https://doi.org/10.5194/gmd-10-2849-2017.

Morton, B., G. I. Taylor, and J. S. Turner, 1956: Turbulent gravitational convection from maintained and instantaneous sources. Proc. Roy. Soc. London, 234A, 1-23, https://doi.org/10.1098/rspa.1956.0011.

Naveira Garabato, A. C., and Coauthors, 2017: Vigorous lateral export of the meltwater outflow from beneath an Antarctic ice shelf. Nature, 542, 219-222, https://doi.org/10.1038/nature20825.

Olbers, D., and H. Hellmer, 2010: A box model of circulation and melting in ice shelf caverns. Ocean Dyn., 60, 141-153, https:// doi.org/10.1007/s10236-009-0252-z.

Paolo, F. S., H. A. Fricker, and L. Padman, 2015: Volume loss from Antarctic ice shelves is accelerating. Science, 348, 327-331, https://doi.org/10.1126/science.aaa0940.

Pauling, A. G., C. M. Bitz, I. J. Smith, and P. J. Langhorne, 2016: The response of the Southern Ocean and Antarctic sea ice to freshwater from ice shelves in an Earth system model. J. Climate, 29, 1655-1672, https://doi.org/10.1175/JCLI-D-15-0501.1.

Pelle, T., M. Morlighem, and J. H. Bondzio, 2019: Brief communication: PICOP, a new ocean melt parameterization under ice shelves combining PICO and a plume model. Cryosphere, 13, 1043-1049, https://doi.org/10.5194/tc-13-1043-2019.

Prince, P. J., and J. R. Dormand, 1981: High order embedded Runge-Kutta formulae. J. Comput. Appl. Math., 7, 67-75, https://doi.org/10.1016/0771-050X(81)90010-3.

Ramadhan, A., and Coauthors, 2020: Oceananigans.jl: Fast and friendly geophysical fluid dynamics on GPUs. J. Open Source Softw., 5, 2018, https://doi.org/10.21105/joss.02018.

Reese, R., T. Albrecht, M. Mengel, X. Asay-Davis, and R. Winkelmann, 2018: Antarctic sub-shelf melt rates via PICO. Cryosphere, 12, 1969-1985, https://doi.org/10.5194/ tc-12-1969-2018.

Rignot, E., J. Mouginot, B. Scheuchl, M. van den Broeke, M. J. van Wessem, and M. Morlighem, 2019: Four decades of Antarctic Ice Sheet mass balance from 1979-2017. Proc. Natl. Acad. Sci. USA, 116, 1095-1103, https://doi.org/10.1073/pnas.1812883116.

Roquet, F., G. Madec, L. Brodeau, and J. Nycander, 2015: Defining a simplified yet "realistic" equation of state for seawater. J. Phys. Oceanogr., 45, 2564-2579, https://doi.org/ 10.1175/JPO-D-15-0080.1.

Rozema, W., H. J. Bae, P. Moin, and R. Verstappen, 2015: Minimum-dissipation models for large-eddy simulation. Phys. Fluids, 27, 085107, https://doi.org/10.1063/1.4928700.

Rye, C. D., A. C. N. Garabato, P. R. Holland, M. P. Meredith, A. G. Nurser, C. W. Hughes, A. C. Coward, and D. J. Webb, 2014: Rapid sea-level rise along the Antarctic margins in response to increased glacial discharge. Nat. Geosci., 7, 732-735, https:// doi.org/10.1038/ngeo2230.

_ J. Marshall, M. Kelley, G. Russell, L. S. Nazarenko, Y. Kostov, G. A. Schmidt, and J. Hansen, 2020: Antarctic glacial melt as a driver of recent Southern Ocean climate trends. Geophys. Res. Lett., 47, e2019GL086892, https:// doi.org/10.1029/2019GL086892.

Sciascia, R., F. Straneo, C. Cenedese, and P. Heimbach, 2013: Seasonal variability of submarine melt rate and circulation in an East Greenland fjord. J. Geophys. Res. Oceans, 118, 2492-2506, https://doi.org/10.1002/jgrc.20142.

Shean, D. E., I. R. Joughin, P. Dutrieux, B. E. Smith, and E. Berthier, 2019: Ice shelf basal melt rates from a high-resolution digital elevation model (DEM) record for Pine Island Glacier, Antarctica. Cryosphere, 13, 2633-2656, https://doi.org/10.5194/ tc-13-2633-2019.

Slater, D., P. Nienow, T. Cowton, D. Goldberg, and A. Sole, 2015: Effect of near-terminus subglacial hydrology on tidewater glacier submarine melt rates. Geophys. Res. Lett., 42, 2861-2868, https://doi.org/10.1002/2014GL062494.

— D. N. Goldberg, P. W. Nienow, and T. R. Cowton, 2016: Scalings for submarine melting at tidewater glaciers from buoyant plume theory. J. Phys. Oceanogr., 46, 1839-1855, https://doi.org/10.1175/JPO-D-15-0132.1.

Speer, K. G., and J. Marshall, 1995: The growth of convective plumes at seafloor hot springs. J. Mar. Res., 53, 1025-1057, https://doi.org/10.1357/0022240953212972.

Straneo, F., G. S. Hamilton, D. A. Sutherland, L. A. Stearns, F. Davidson, M. O. Hammill, G. B. Stenson, and A. RosingAsvid, 2010: Rapid circulation of warm subtropical waters in a major glacial fjord in East Greenland. Nat. Geosci., 3, 182-186, https://doi.org/10.1038/ngeo764.

Swart, N., and J. Fyfe, 2013: The influence of recent Antarctic ice sheet retreat on simulated sea ice area trends. Geophys. Res. Lett., 40, 4328-4332, https://doi.org/10.1002/grl.50820.

Taylor, K. E., R. J. Stouffer, and G. A. Meehl, 2012: An overview of CMIP5 and the experiment design. Bull. Amer. Meteor. Soc., 93, 485-498, https://doi.org/10.1175/BAMS-D-11-00094.1.

Thurnherr, A. M., S. Jacobs, P. Dutrieux, and C. Giulivi, 2014: Export and circulation of ice cavity water in Pine Island Bay, West Antarctica. J. Geophys. Res. Oceans, 119, 1754-1764, https://doi.org/10.1002/2013JC009307.

Timmermann, R., and Coauthors, 2010: A consistent data set of Antarctic ice sheet topography, cavity geometry, and global bathymetry. Earth Syst. Sci. Data, 2, 261-273, https://doi.org/ 10.5194/essd-2-261-2010.

Turner, J., 1986: Turbulent entrainment: The development of the entrainment assumption, and its application to geophysical flows. J. Fluid Mech., 173, 431-471, https://doi.org/10.1017/ S0022112086001222.

—, T. J. Bracegirdle, T. Phillips, G. J. Marshall, and J. S. Hosking, 2013: An initial assessment of Antarctic sea ice extent in the CMIP5 models. J. Climate, 26, 1473-1484, https:// doi.org/10.1175/JCLI-D-12-00068.1.

Vallis, G. K., 2017: Atmospheric and Oceanic Fluid Dynamics. Cambridge University Press, 745 pp., https://doi.org/10.1017/ 9781107588417.

Verstappen, R., 2018: How much eddy dissipation is needed to counterbalance the nonlinear production of small, unresolved scales in a large-eddy simulation of turbulence? Comput. Fluids, 176, 276-284, https://doi.org/10.1016/j.compfluid.2016.12.016.

Vreugdenhil, C. A., and J. R. Taylor, 2018: Large-eddy simulations of stratified plane Couette flow using the anisotropic minimumdissipation model. Phys. Fluids, 30, 085104, https://doi.org/ 10.1063/1.5037039.

Xu, Y., E. Rignot, D. Menemenlis, and M. Koppes, 2012: Numerical experiments on subaqueous melting of Greenland tidewater glaciers in response to ocean warming and enhanced subglacial discharge. Ann. Glaciol., 53, 229-234, https://doi.org/10.3189/ 2012AoG60A139.

,-- I. Fenty, D. Menemenlis, and M. M. Flexas, 2013: Subaqueous melting of Store Glacier, west Greenland from three-dimensional, high-resolution numerical modeling and ocean observations. Geophys. Res. Lett., 40, 4648-4653, https:// doi.org/10.1002/grl.50825. 